\title{
Risk factors associated with scabies infestation among primary schoolchildren in a low socio-economic area in southeast of Iran
}

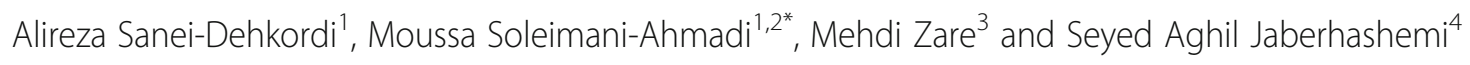

\begin{abstract}
Background: Scabies is a neglected tropical disease caused by the mite Sarcoptes scabiei that burrows under the skin. It is a major health problem in tropical areas, largely affecting children. Scabies is common and highly contagious and in schoolchildren spreads quite rapidly, due to overcrowding and close contact within the schools. This study aimed to determine the risk factors associated with scabies infestation among primary schoolchildren in Bashagard County, one of the low socio-economic areas in southeast of Iran.

Methods: To conduct this community-based, descriptive, and cross-sectional study, four primary schools were randomly selected in the Bashagard County. All students in these schools were selected and examined for scabies. Clinical examination and sociodemographic profile of students were assessed using a pre-tested structured questionnaire. Chi-square test, and binary logistic regression were used to analyse the factors associated with scabies infestation by SPSS version 21 software.

Results: Out of 480 studied schoolchildren, 15 cases of scabies with a prevalence of $3.1 \%$ were observed. The frequency of infestation in males was $1.6 \%$ and it was $4.7 \%$ in females. Independent factors associated with a high risk of scabies infestation in unadjusted analysis were being student of grade $5-6$ ( $\mathrm{cOR}=13.12,95 \% \mathrm{Cl} 2.92-58.89$, $p=0.0001)$, low educational level of father ( $\mathrm{COR}=4.37,95 \% \mathrm{Cl} 0.97-19.59, p=0.036)$, low educational level of mother ( $\mathrm{cOR}=4.14,95 \% \mathrm{Cl} 1.92-18.57, p=0.045)$, joblessness of father ( $\mathrm{COR}=14.77,95 \% \mathrm{Cl} 4.97-43.89, p=0.0001)$, employment of mother ( $\mathrm{cOR}=5.28,95 \% \mathrm{Cl} 1.38-20.16, p=0.007$ ), large family size ( $\mathrm{cOR}=3.34,95 \% \mathrm{Cl} 1.05-10.64$, $p=0.031)$, use of shared articles ( $\mathrm{COR}=33.37,95 \% \mathrm{Cl} 10.82-102.90, p=0.0001)$, and absence of bathroom in the house $(\mathrm{COR}=11.77,95 \% \mathrm{Cl} 2.16-63.94, p=0.0001)$.
\end{abstract}

\footnotetext{
* Correspondence: mussa.sahmadi@gmail.com

'Social Determinants in Health Promotion Research Center, Hormozgan

University of Medical Sciences, Bandar Abbas, Bandar Abbas, Iran

${ }^{2}$ Department of Medical Entomology and Vector Control, Faculty of Health,

Hormozgan University of Medical Sciences, P.O. Box: 79145-3838, Bandar

Abbas, Iran

Full list of author information is available at the end of the article
}

(c) The Author(s). 2021 Open Access This article is licensed under a Creative Commons Attribution 4.0 International License, which permits use, sharing, adaptation, distribution and reproduction in any medium or format, as long as you give appropriate credit to the original author(s) and the source, provide a link to the Creative Commons licence, and indicate if changes were made. The images or other third party material in this article are included in the article's Creative Commons licence, unless indicated otherwise in a credit line to the material. If material is not included in the article's Creative Commons licence and your intended use is not permitted by statutory regulation or exceeds the permitted use, you will need to obtain permission directly from the copyright holder. To view a copy of this licence, visit http://creativecommons.org/licenses/by/4.0/ The Creative Commons Public Domain Dedication waiver (http://creativecommons.org/publicdomain/zero/1.0/) applies to the data made available in this article, unless otherwise stated in a credit line to the data. 
Conclusions: Results of this study confirmed that scabies is still one of the most important health problems in the primary schools of the Bashagard County. Low socioeconomic status and personal hygiene of the schoolchildren were the most important factors influencing the prevalence of scabies. Improvement of socioeconomic conditions and implementation of appropriate educational programs and active surveillance system to quickly detect and treat scabies cases are necessary in order to reduce the prevalence of scabies in schoolchildren in this area.

Keywords: Scabies, Prevalence, Risk factors, Primary schoolchildren, Bashagard, Iran

\section{Background}

Scabies is a skin infestation caused by Sarcoptes scabiei var. hominis, an obligate parasite mite which burrows in the lower stratum corneum of the skin [1].

The annual world burden of scabies is estimated to be 300 million cases [2]. It is more prevalent in tropical and humid regions and was listed as a neglected tropical disease (NTD) by the WHO in 2013 [3]. The major clinical manifestations of scabies is a generalized pruritic rash, worsening at night [4]. Scabies is transmitted through close personal contact, as well as through infected clothing. Although it is associated with low morbidity, scabies can lead to dermatitis, intense itching, and secondary bacterial infections [5]. It can also cause psychological frustration and intense anxiety among the infected people [6]. The most common sites of infestation are the wrists, buttocks, fingers, genitals, axillae, groins, and the breasts in women. In young children and infants, the soles, palms, neck, and face are involved more commonly [7].

Epidemiological studies have shown that the prevalence of scabies infestations is not influenced by race, age, or sex and the main contributing factors are poor hygiene, poverty, and overcrowded living conditions [8].

Scabies affects all social classes, however, some groups of people, such as immunocompromised individuals, the elderly, residents of care facilities, children, and populations with low socioeconomic conditions, are at higher risk of infection [9].

Scabies is a common problem in schoolchildren and the infestation spreads rapidly due to close physical contact between classmates and overcrowding conditions in the schools $[10,11]$.

Scabies has a different epidemiological distribution among different communities [12]. In Iran, most of the epidemiological studies about scabies have been conducted among prisoners and military personnel. Results of these studies indicated that sociodemographic factors such as educational level, family size, and level of personal hygiene influence the prevalence of scabies in these populations. However, few studies have reported the prevalence of scabies and its related factors in schoolchildren [13]. Therefore, it is important to recognize the factors that may influence the prevalence of scabies to provide basic information for interventions toward the prevention and control of infestation in schoolchildren. This study aimed to determine the risk factors associated with scabies infestation among primary schoolchildren in Bashagard County, one of the low socio-economic areas in southeast of Iran.

\section{Methods}

\section{Study areas}

This study was conducted in Bashagard County in the Hormozgan Province, southeast of Iran. This County has an area of $16,000 \mathrm{~km}^{2}$ and is placed between longitudes $57^{\circ} 23^{\prime}-59^{\circ} 02^{\prime} \mathrm{E}$ and latitudes $26^{\circ} 04^{\prime}-26^{\circ} 58^{\prime} \mathrm{N}$, with 35,085 populations according to 2016 census, from which 51 and $49 \%$ were males and females, respectively [14]. The area is hilly with low precipitation. It has a hot and dry climate. In this county, the average annual rainfall is $262 \mathrm{~mm}$ and the averages of maximum and minimum relative humidity are respectively $47 \%$ in February and $17 \%$ in May. The climate in this region is tropical with a mean annual temperature of $26.7{ }^{\circ} \mathrm{C}$, ranging from 15.3 to $36.4{ }^{\circ} \mathrm{C}$ (Fig. 1).

According to the latest divisions of the country in 2016, Bashagard county has 2 city and 227 villages. The villages are scattered and small with low number of population and are located close to permanent and seasonal rivers [14]. This County is an undeveloped and remote area in the Hormozgan province. Most of the people in this area are poor and live in houses made of cement blocks and shelters.

\section{Study design and sample size}

On the basis of unpublished epidemiological data on the prevalence of scabies infestation in Bashagard health center, Bashagard County was considered to be investigated. In this regard, a community-based descriptive cross-sectional study was conducted from October to December 2018 in this County. To calculate the sample size, the maximum variability was assumed to be $7 \%$ [15]. With $95 \%$ confidence level and $\pm 2.3 \%$ precision, the minimum number of subjects was determined using the formula $\left(n=z^{2} p q / d^{2}\right)$ to be 472 . A multi-stage cluster sampling method was used to select the primary schoolchildren. There were two cities and four villages in the Countiy that had the inclusion criteria and in the first stage all of them were considered as the clusters. In 


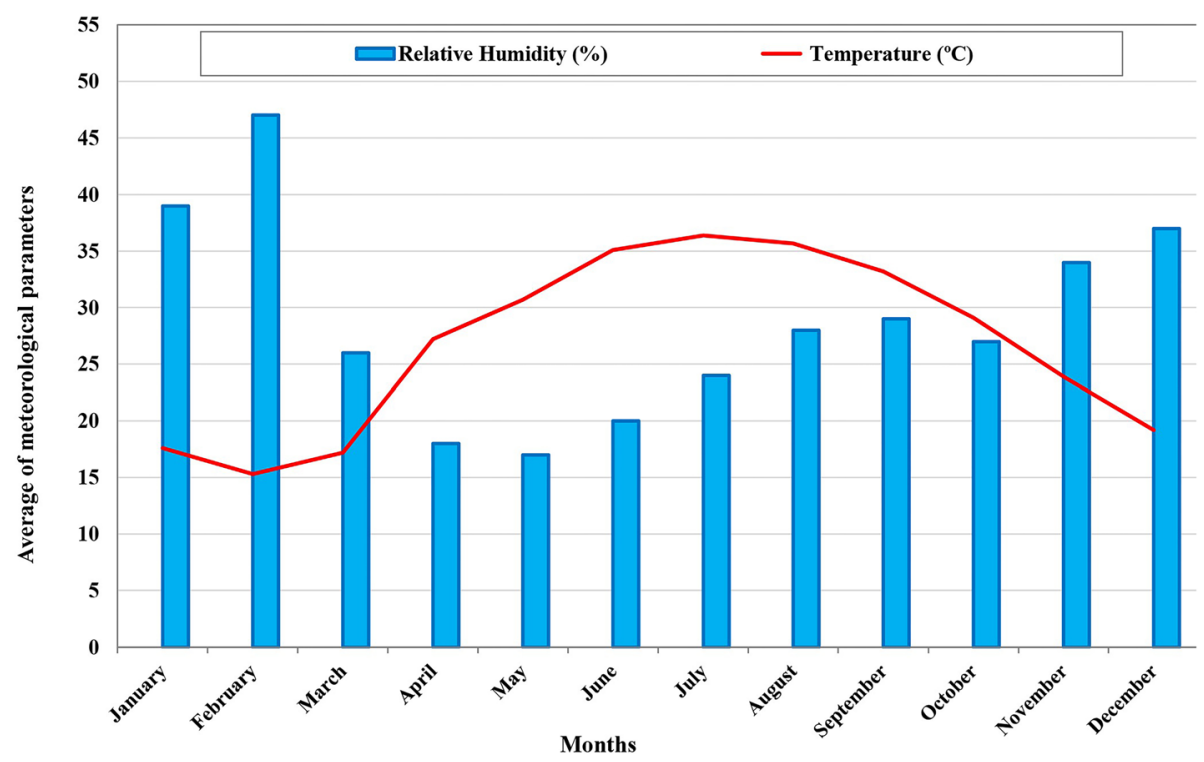

Fig. 1 Average of meteorological parameters in Bashagard County, southeast Iran, 2018

the next stage, two cities and two villages were selected according to their population. All of the schools and students in the selected clusters were considered as the study subjects. In this regard, two urban schools in Gouharan and Sardasht cities and two rural schools in Ahven and Kooh-e-heydar villages were enrolled in the study (Fig. 2).

All of the schoolchildren in the clusters were examined for scabies. Clinical examinations were performed in a private room for all of the students in each school by a trained physician. In the first step, suspected scabies cases were identified according to the presence of burrows or erythematous papular, vesicular, and pustular lesions with itching. In the next step, sampling of borrows of the patient by scraping test methods was used only in suspected cases to confirm the scabies infestation [10]. After the examination, all of the schoolchildren were interviewed by a structured questionnaire. Before using the questionnaire, its reliability and validity was tested. In this regard, content validity ratio (CVR) and content validity index (CVI) were used to validate the questionnaire $[16,17]$.The results of CVI and CVR were satisfactory for all items. In this regard, the CVI ranged from 0.82 to 1.00 and CVR ranged from 0.72 to 1.00 ).

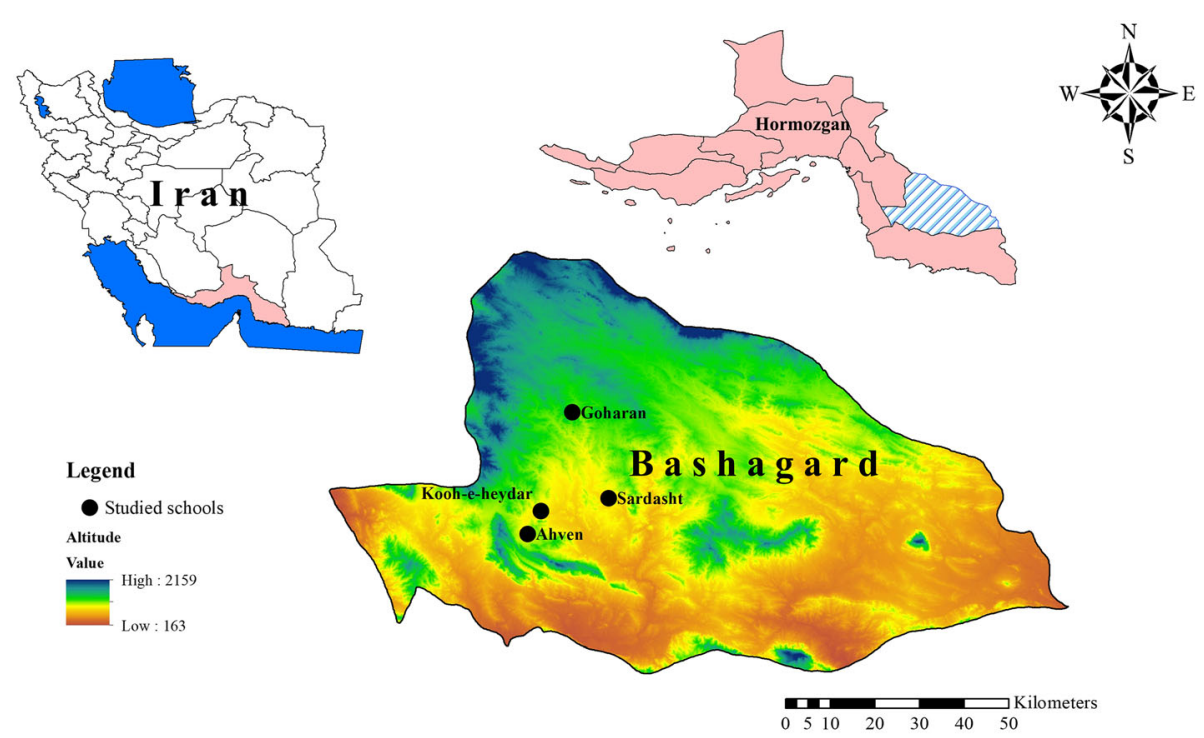

Fig. 2 Map showing the location of study schools in Bashagard County, Hormozgan province, southeast Iran 
Internal consistency of the questionnaire was evaluated by calculating Cronbach's alpha coefficient [18]. Testretest reliability was also determined by completing the questionnaire twice during a two-week interval by 40 participants. The intra-class correlation coefficient (ICC) was calculated to determine the stability of the questionnaire over the time [19]. Internal consistency of the questionnaire and its test-retest reliability were also satisfactory (Cronbach's alpha $=0.88$ and ICC $=0.87$ ).

The questionnaires were directed by trained interviewers and supervised by the principal investigator. The questionnaire included different items such as demographic characteristics, presence of health teacher in the schools, parent's educational level, parent's job, family size, bathroom availability in the home, and construction materials and water supply of living houses.

\section{Statistical analysis}

To analyze the data, SPSS ver.21 software was used. Descriptive statistics were used to show averages, percentages, and relative frequencies. Chi-square test and binary logistic regression model were used to analyze the data. For every potential predictors of scabies infestation, odd ratio (OR) obtained from bivariate logistic regression model and $95 \%$ confidence intervals $(\mathrm{CI})$ were reported. The results were considered significant at $5 \%$ level $(p$-value $<0.05)$.

\section{Inclusion and exclusion criteria}

The inclusion criteria were being the students of a primary school with the students of different grades in separated classrooms and willing to participate in the study.

The exclusion criteria were unwilling to participate in the study and being absent at the time of visiting.

\section{Results}

A total of 480 students including $257(53.3 \%)$ males and $223(46.5 \%)$ females were examined. The average of students' age was $9.6 \pm 1.77$ years, ranging from 6 to 13 years. The mean family size was $5.4 \pm 2.2$ persons, ranging from 2 to 13 persons. Nearly $88 \%$ of the schoolchildren were living in houses constructed using cement blocks. Majority of the schoolchildren had access to sanitary tap water $(94.2 \%)$, and all of them had electricity in their houses. In addition, $98.3 \%$ of them had bathroom in their houses (Table 1).

Majority of the fathers of schoolchildren $(60.6 \%)$ were either illiterate or had a primary level of education, also, $93.1 \%$ of the children's fathers were employed. In addition, most of the children's mothers $(61.9 \%)$ were either illiterate or had only received a primary education, and $95 \%$ were housewives (Table 2).

In this study Sarcoptes scabiei (Fig. 3) was detected on the skin lesions of 15 out of 480 schoolchildren.
Table 1 House characteristics of schoolchildren in Bashagard County, southeast Iran

\begin{tabular}{lll}
\hline Characteristics & Number & Precent \\
\hline Type of house & 422 & 87.9 \\
Cement- blockhouse & 44 & 9.2 \\
Muddy & 14 & 2.9 \\
Shed & & \\
Water supply & 452 & 94.2 \\
Yes & 28 & 5.8 \\
No & & \\
Electricity & 480 & 100 \\
Yes & 0 & 0 \\
No & & \\
Bathroom availability in house & 472 & 98.3 \\
Yes & 8 & 1.7 \\
No &
\end{tabular}

Accordingly, the prevalence of scabies among schoolchildren was $3.1 \%$. The frequency of infestation in male and female students were 1.5 and $4.9 \%$, respectively, and females were more likely than males to be infected by scabies (OR $=3.28,95 \%$ CI 1.03-10.45, $p=0.034$; Table 2).

Itching was the most prevalent symptom (84.6\%), with $64 \%$ presenting severe itching and $49 \%$ complained of itching-related sleep disturbance. Moreover, Erythematous nodules were the most common skin lesions in the students (Fig. 4).

As Fig. 5 indicates, lesions were observed on the web space between the fingers (33.3\%), wrists $(20 \%)$, abdomen $(13.3 \%)$, forearms and arms $(13.3 \%)$, thighs $(6.7 \%)$, anterior axillary folds $(6.7 \%)$, and legs $(6.7 \%)$.

The study showed that the prevalence of scabies was significantly higher in the grade 5-6 students and the students in these grades were more likely to develop scabies than grade $1-4$ students $(\mathrm{OR}=13.12,95 \% \mathrm{CI}$ 2.92-58.89, $p=0.0001$; Table 2).

The study results also indicated that the prevalence of scabies was significantly related to the parents' educational level. In this regard, lower levels of education for either the father or the mother were found to increase the risk of scabies significantly $(\mathrm{OR}=4.37,95 \%$ CI $0.97-$ 19.59, $p=0.036$ for paternal education; and $\mathrm{OR}=4.14$, $95 \%$ CI $1.92-18.57, p=0.045$ for maternal education; Table 2).

According to the results, scabies infestation was significantly related to the parents' job. The risk of scabies infestation was higher in schoolchildren whose fathers were jobless $(\mathrm{OR}=14.77,95 \%$ CI 4.97-43.89, $p=$ $0.0001)$, and the students with employed mothers had higher risk of infestation $(\mathrm{OR}=5.28,95 \%$ CI 1.38-20.16, $p=0.007$; Table 2). 
Table 2 Sociodemographic characteristics associated with scabies infestation in schoolchildren of Bashagard County, southeast Iran

\begin{tabular}{|c|c|c|c|c|c|c|}
\hline \multirow[t]{2}{*}{ Characteristics } & \multicolumn{2}{|c|}{ Total examined cases } & \multicolumn{2}{|c|}{ Positive cases } & \multirow{2}{*}{$\begin{array}{l}\text { Crude OR (95\% } \\
\text { Cl) }\end{array}$} & \multirow[t]{2}{*}{$p$-value } \\
\hline & No. & $\%$ & No. & $\%$ & & \\
\hline \multicolumn{7}{|l|}{ Sex } \\
\hline Males & 257 & 53.5 & 4 & 1.5 & 1 & 0.034 \\
\hline Females & 223 & 45.5 & 11 & 4.9 & $3.28(1.03-10.45)$ & \\
\hline \multicolumn{7}{|l|}{ School grade } \\
\hline $1-4$ & 313 & 65.2 & 2 & 0.6 & 1 & 0.0001 \\
\hline $5-6$ & 167 & 34.8 & 13 & 7.78 & $13.12(2.92-58.89)$ & \\
\hline \multicolumn{7}{|l|}{ Father's education } \\
\hline Illiterate/ Primary & 291 & 60.6 & 13 & 4. 4 & 1 & 0.036 \\
\hline Secondary/ High school/ University & 189 & 39.4 & 2 & 1 & $4.37(0.97-19.59)$ & \\
\hline \multicolumn{7}{|l|}{ Mother's education } \\
\hline Illiterate/ Primary & 297 & 61.9 & 13 & 4.4 & $4.14(1.92-18.57)$ & 0.045 \\
\hline Secondary/ High school/ University & 183 & 38.1 & 2 & 1.1 & 1 & \\
\hline \multicolumn{7}{|l|}{ Father's Job } \\
\hline Employee/ Farmer/ Self-employment & 447 & 93.1 & 8 & 1.8 & 1 & 0.0001 \\
\hline Jobless & 33 & 6.9 & 7 & 21.2 & $14.77(4.97-43.89)$ & \\
\hline \multicolumn{7}{|l|}{ Mother's Job } \\
\hline Employee & 24 & 5 & 3 & 12.5 & $5.28(1.38-20.16)$ & 0.007 \\
\hline Housewife & 456 & 95 & 12 & 2.6 & 1 & \\
\hline \multicolumn{7}{|l|}{ Family size } \\
\hline $2-4$ & 259 & 53.9 & 4 & 1.5 & 1 & 0.031 \\
\hline$>4$ & 221 & 46.1 & 11 & 4.8 & $3.34(1.05-10.64)$ & \\
\hline
\end{tabular}

OR Odds ratio, $\mathrm{Cl}$ Confidence interval

In this study, infestation rate of scabies was positively associated with family size and the risk of scabies infestation was higher in the crowded families with more than four members $(\mathrm{OR}=3.34,95 \%$ CI 1.05-10.64, $p=0.031$; Table 2).

The study results also showed that the prevalence of scabies infestation was $31 \%$ among schoolchildren who used shared articles such as towel, combs, and cloth and they were more likely to be infested by scabies than students who did not use shared articles (OR $=33.37,95 \%$ CI 10.82-102.90, $p=0.0001$; Table 3). In addition, the prevalence of scabies infestation was higher among students with shared bedroom compared to those with private bedroom. However, sharing the bedroom was not

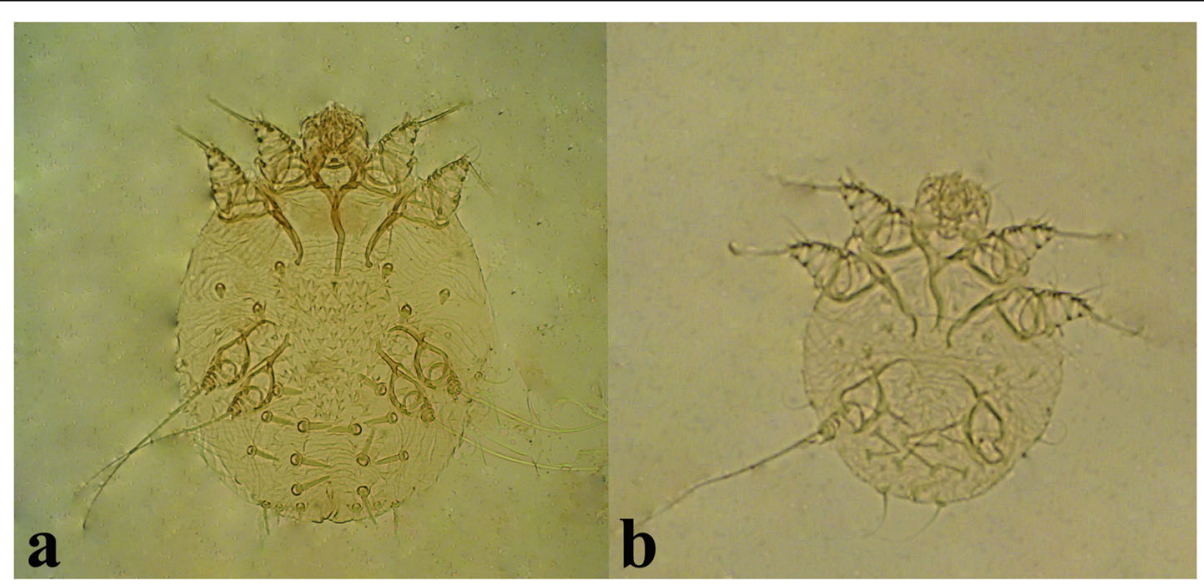

Fig. 3 Scabies mite detected on the scrapings of the skin legions in schoolchildren of Bashagard County, south of Iran. Adult mite (a), Larvae (b) 


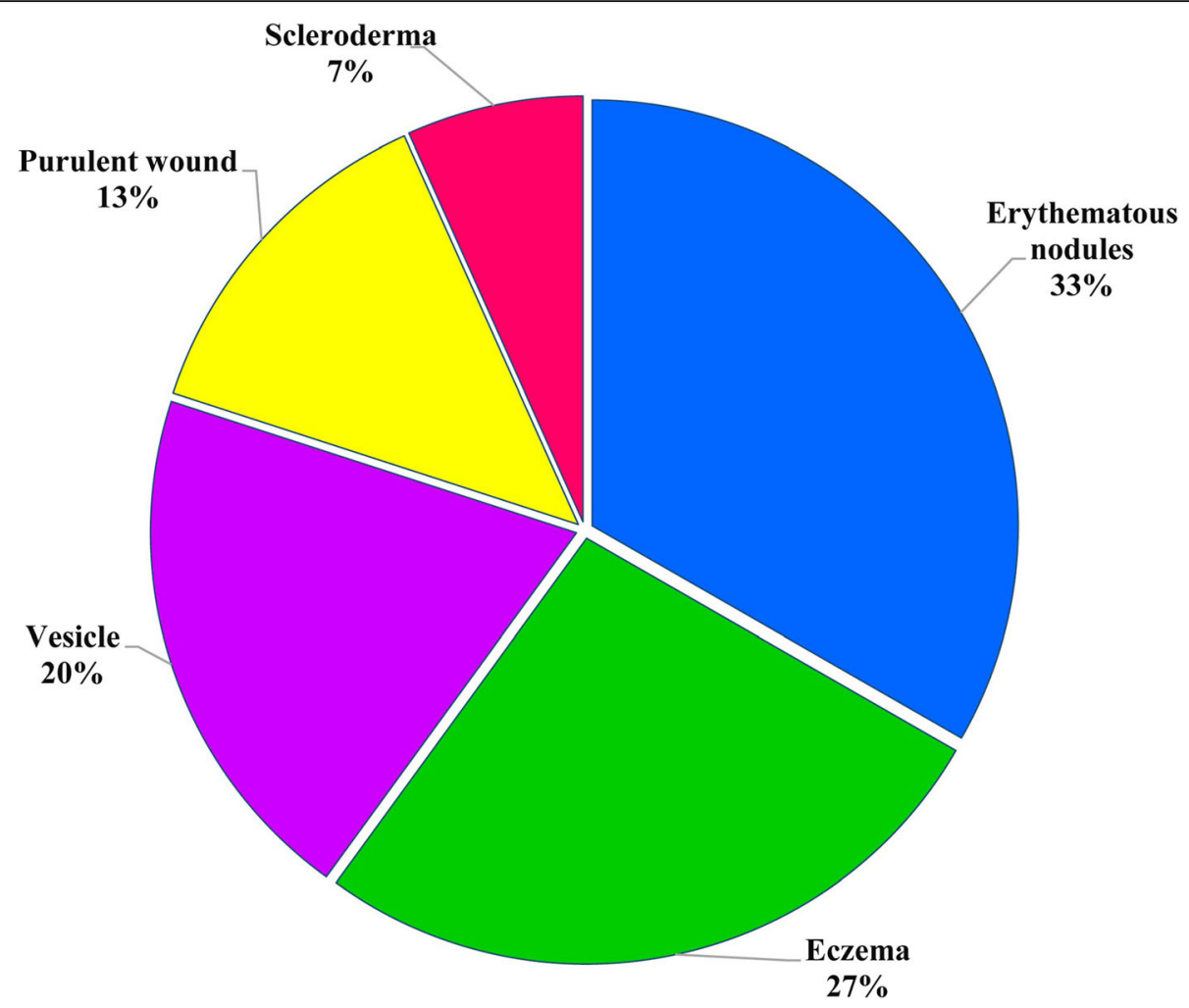

Fig. 4 Various forms of scabies lesions in schoolchildren of Bashagard County, southeast Iran

found to affect the risk of infestation significantly (OR = 1.76, $95 \%$ CI 0.23-13.68, $p=0.58$; Table 3).

In the present study, the risk of scabies infestation was significantly higher among the students who did not have bathroom in their houses compared to those who had bathroom $(\mathrm{OR}=11.77,95 \%$ CI 2.16-63.94, $p=0.0001$; Table 3).

\section{Discussion}

Epidemiological studies about scabies infestation provide valuable information about the associated risk factors and serve as a basis for selection of prevention methods and control and therapeutic services. According to the results of this study, the prevalence of scabies was $3.1 \%$ in primary schoolchildren of Bashagard County, with higher infestation rate in female students $(4.7 \%)$, compared to that of males $(1.6 \%)$. Previous studies have reported the prevalence of scabies infestation in primary schoolchildren from 2.09 to $7.22 \%$ in different parts of Iran [13, 20-23]. In similar studies, conducted on schoolchildren of Egypt, Nigeria, Turkey, and, Kuwait, the prevalence of scabies was $4.4 \%, 4.8 \%, 2.16 \%$, and $3 \%$, respectively [24-27]. In addition, studies from India and Cameron have reported high infestation rate of scabies among schoolchildren with the prevalence of 39.42 and $17.8 \%$, respectively $[28,29]$. The variation of scabies infestation rate may be due to different factors such as family size, personal hygiene, and economic conditions $[30,31]$. Prevalence of scabies infestation in the study area can be attributed to factors such as use of shared articles, low parents' educational level, large family size, low frequency of bathing per week, and poor health facilities. Obviously, many of these factors are the result of extreme poverty.

In this study, the most common locations of scabies lesions were the web spaces between the fingers and wrists. A similar study in the north of Iran also reported the highest number of scabies infestation on the web spaces between the fingers [22]. Scabies infections are usually localized in specific parts of the body and elbows, wrists, and hands are the most commonly infected sites [32]. Hand and wrist infection may occur due to handling mite-contaminated materials and touching infected persons. However, the distribution patterns suggest that the mites select special locations of the body and these locations may be preferred partly according to the lipid composition [32, 33].

In this study the highest prevalence of scabies infestation was observed in the grade 5-6 students and in children aging more than 10 years. This finding is in accordance with the results of previous studies in Brazil, Nigeria, Pakistan, and Sri Lanka [7, 34-36]. This can be explained by the more direct physical contact with friends at this students' age group. In this regards, other 

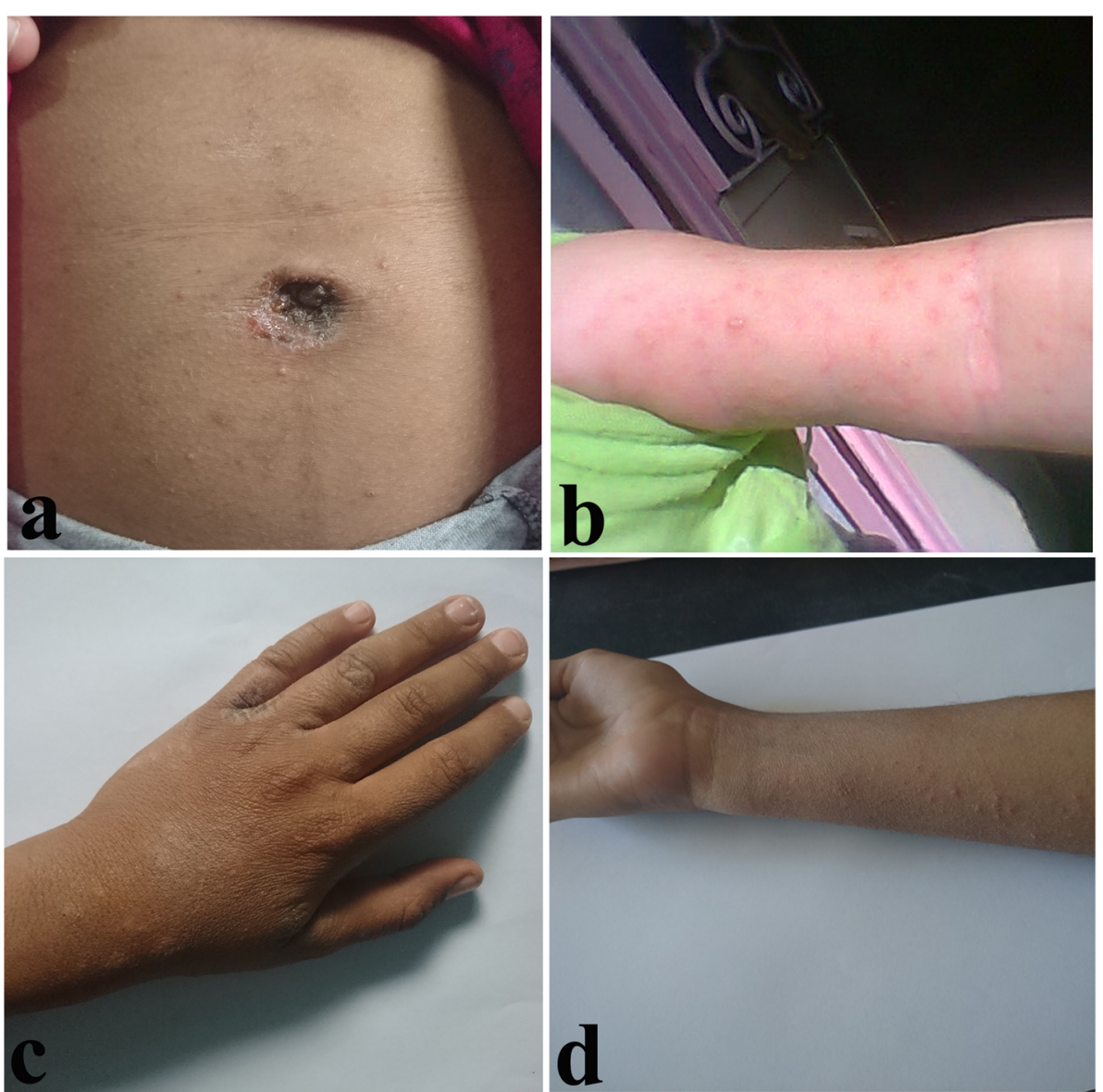

Fig. 5 Locations of scabies infestation in schoolchildren of Bashagard County, southeast Iran. abdominal area (a), arm (b), web spaces between the fingers (c), and forearm (d)

studies also have reported the important role of physical contacts in transmission of scabies [35].

According to the results, scabies was more prevalent among schoolchildren with low educated parents. Similar findings have been reported from Iran [22, 23, 26, 37-40]. Parental education seems to have a major role in prevention of contagious diseases. Many studies have reported that parents with higher levels of education are more capable to apply healthcare and prevention measures for their children [26, 39-41]. Since educationalbased interventions have been reported to be efficient in reduction of insect-borne diseases in low socioeconomic

Table 3 Behavioral characteristics associated with scabies infestation in schoolchildren of Bashagard County, southeast Iran

\begin{tabular}{|c|c|c|c|c|c|c|}
\hline \multirow[t]{2}{*}{ Characteristics } & \multicolumn{2}{|c|}{ Total examined cases } & \multicolumn{2}{|c|}{ Positive cases } & \multirow{2}{*}{$\begin{array}{l}\text { Crude OR (95\% } \\
\text { Cl) }\end{array}$} & \multirow[t]{2}{*}{$p$-value } \\
\hline & No. & $\%$ & No. & $\%$ & & \\
\hline \multicolumn{7}{|c|}{ Use of shared articles } \\
\hline Yes & 29 & 6.1 & 9 & 31.0 & $33.37(10.82-102.90)$ & 0.0001 \\
\hline No & 451 & 93.9 & 6 & 1.3 & 1 & \\
\hline \multicolumn{7}{|c|}{ Sharing bedroom } \\
\hline Yes & 427 & 89.2 & 14 & 3.3 & $1.76(0.23-13.68)$ & 0.583 \\
\hline No & 53 & 10.8 & 1 & 1.9 & 1 & \\
\hline \multicolumn{7}{|c|}{ Bathroom availability in house } \\
\hline Yes & 472 & 98.3 & 13 & 2.7 & 1 & 0.0001 \\
\hline No & 8 & 1.7 & 2 & 25 & $11.77(2.16-63.94)$ & \\
\hline
\end{tabular}

OR Odds ratio, $\mathrm{Cl}$ Confidence interval 
areas [42], it is essential to provide appropriate educational programs for teachers, parents, and students to increase their awareness about scabies infestation risk factors and related prevention measures [4].

The results of the present study have confirmed the positive relationship between scabies infestation and the family size. This finding is supported by previous studies in Iran, Saudi Arabia, Cameroon, Ethiopia, Fiji, Mali, Malawi, and Cambodia [21-23, 29, 38, 43-45]. Larger family size leads to overcrowding. In the overcrowded homes, close contact between family members and use of shared beds and cloths, increases the risk of scabies transmission. In addition, having more children may result in higher scabies infestation rates, because parents with more children pay less time per child to perform laundry and other personal hygiene activities.

According to the results of this study, use of shared articles such as towel, combs, and cloth affects the scabies prevalence. In a similar study conducted by Karim et al. in Bangladesh [40], children who had shared beds on the floor, contracted more severe scabies infections and became re-infected more frequently. It was attributed to the use of shared beds which facilitates skin-to-skin contact and transmission of scabies from infested children to healthy ones. Similar findings have been reported from Egypt, Pakistan, Brazil, Ethiopia, Argentina, and Taiwan [26, 35, 39, 46-48]. In the crowded conditions, use of shared beds, cloths, and other materials may transmit the scabies infestation [48].

The present study revealed that the prevalence of scabies was higher among schoolchildren who had no bathroom in their homes. This finding is similar to the results of Wochebo et al. study in Ethiopia who reported the risk of scabies is significantly associated with personal hygiene and children who took bath less than two times a week were five times more likely to be infected by scabies [46]. Likewise, in previous studies conducted in Ethiopia, Nigeria, Saudi Arabia, Bangladesh, and Cameroon an association between scabies infestation and frequency of bathing was reported [11, 34, 38, 40, 42]. This might be because primary school students have less control over their personal hygiene. In addition, since schoolchildren spend much of their time with their friends, they have a higher chance of physical contact which facilitates scabies transmission. Other studies also have confirmed that the prevalence of human scabies is linked with poor personal hygiene $[10,49]$. Therefore, the prevalence of scabies infestation in primary school children may be, to some extent, due to low awareness and practice regarding the personal hygiene.

\section{Conclusions}

Results of this study confirmed that scabies is still one of the most important health problems in the primary schools of Bashagard County.
Low parents' educational level, father's joblessness, employment of mother, large family size, use of shared articles such as towel, comb, and cloth, absence of bathroom in the house, and poor health facilities were recognized as significant sociodemographic factors associated with prevalence of scabies among primary schoolchildren in the study area. Implementation of appropriate health education programs for students and their parents is necessary to increase their awareness about scabies risk factors and the preventive measures for successful management of scabies in schoolchildren. In addition, implementation of an active surveillance system for early case detection by medical staff and periodic clinical check-ups for schoolchildren to provide early treatment, particularly in rural areas, is necessary.

\section{Limitations of the study}

This study was conducted only during the autumn season, and since scabies is claimed to show higher incidence during the winter months, the findings cannot be used to determine the annual prevalence of scabies among schoolchildren in the study area. Moreover, multi-variable analysis could not be conducted due to low prevalence of disease among the sub-categories.

\section{Abbreviations \\ NTD: Neglected tropical disease; OR: Odds ratio; Cl: Confidence interval; CVR: Content validity ratio; CVI: Content validity index}

\section{Acknowledgements}

The authors of this article are grateful for the support of the director and the staff of Bashagard Health Center who cooperated and participated in this study.

\section{Authors' contributions}

All the authors contributed to the conception and design of the study. "MSA, and MZ drafted the manuscript. MSA and ASD participated in the data analysis. SAJ performed the data collection, and trained field researcher. All authors read and approved the final manuscript".

\section{Funding}

This study received financial support from Research and Technology Deputy of Hormozgan University of Medical Sciences (Project No.24.524).

Availability of data and materials

The data are available from the corresponding author on reasonable request.

\section{Declarations}

Ethics approval and consent to participate

This study was confirmed by Ethical Committee of Hormozgan University Medical Sciences (Code No: IR.HUMS.REC.1398.273). The participation in the study was voluntary and the participants were free to withdraw from the

study at any time. Students and their parents had received an adequate and understandable explanation about the intent of the study, the possible

results, their meaning, and signed the informed consent form. Besides, the data were collected anonymously after obtaining informed verbal consent that approved by the ethics committee from students and their parents. In this study identification numbers were used instead of participant names and collected data were kept confidential. In this study, all methods were carried out in accordance with relevant guidelines and regulations.

Consent for publication

Not applicable. 


\section{Competing interests}

The authors declare that they have no competing interests.

\begin{abstract}
Author details
${ }^{1}$ Social Determinants in Health Promotion Research Center, Hormozgan University of Medical Sciences, Bandar Abbas, Bandar Abbas, Iran. ${ }^{2}$ Department of Medical Entomology and Vector Control, Faculty of Health, Hormozgan University of Medical Sciences, P.O. Box: 79145-3838, Bandar Abbas, Iran. ${ }^{3}$ Department of Occupational Health Engineering, Faculty of Health, Hormozgan University of Medical Sciences, Bandar Abbas, Iran. ${ }^{4}$ Bashagard Health Center, Hormozgan University of Medical Sciences, Bashagard, Iran.
\end{abstract}

\section{Received: 18 January 2021 Accepted: 19 May 2021}

Published online: 25 May 2021

\section{References}

1. Leung AKC, Lam JM, Leong KF. Scabies: A Neglected Global Disease. Curr Pediatr Rev. 2020;16(1):33-42.

2. Hengge UR, Currie BJ, Jäger G, Lupi O, Schwartz RA. Scabies: a ubiquitous neglected skin disease. Lancet Infect Dis. 2006;6(12):769-79.

3. Thomas J, Peterson GM, Walton SF, Carson CF, Naunton M, Baby KE. Scabies: an ancient global disease with a need for new therapies. BMC Infect Dis. 2015;15:250

4. Buczek A, Pabis B, Bartosik K, Stanislawek IM, Salata M, Pabis A. Epidemiological study of scabies in different environmental conditions in central Poland. Ann Epidemiol. 2006;16(6):423-28.

5. Salavastru CM, Chosidow O, Boffa MJ, Janier M, Tiplica GS. European guideline for the management of scabies. J Eur Acad Dermatol Venereol. 2017;31(8):1248-1253.

6. Osinubi O, Grainge MJ, Hong L, Ahmed A, Batchelor J, Grindlay D, et al. The prevalence of psychological comorbidity in people with vitiligo: a systematic review and meta-analysis. Br J Dermatol. 2018;178(4):863-78

7. Heukelbach J, Wilcke T, Winter B, Feldmeier H. Epidemiology and morbidity of scabies and pediculosis capitis in resource-poor communities in Brazil. $\mathrm{Br}$ J Dermatol. 2005;153(1):150-6.

8. Feldmeier $\mathrm{H}$, Heukelbach J. Epidermal parasitic skin diseases: a neglected category of poverty-associated plagues. Bull World Health Organ. 2009;87(2):152-9.

9. Mounsey KE, McCarthy JS, Walton SF. Scratching the itch: new tools to advance understanding of scabies. Trends Parasitol. 2013;29(1):35-42.

10. Andrews RM, McCarthy J, Carapetis JR, Currie BJ. Skin disorders, including pyoderma, scabies, and tinea infections. Pediatr Clin North Am. 2009;56(6): 1421-40.

11. Dagne H, Dessie A, Destaw B, Yallew WW, Gizaw Z. Prevalence and associated factors of scabies among schoolchildren in Dabat district, northwest Ethiopia, 2018. Environ Health Prev Med. 2019;24(1):67.

12. Neglected tropical diseases, scabies. 2019. Available from: https://www.who, int/neglected_diseases/diseases/scabies/en/. Accessed 5 Jan 2021.

13. Dehghani R, Ghannaee Arani M, Zarghi I. Scabies contamination status in Iran: A review. Int J Epidemiol Res. 2016;3(1):86-94.

14. Statistics Center of Iran. General census of population and housing. 2016. Available at: https://www.amar.org.ir/english

15. Dehghani R, Vazirianzadeh B, Hejazi SH, Jalayer N. Frequency of Sarcoptes scabiei infestation in patients referred to the parasitology laboratory in Isfahan, Iran (1996-2002). Jundishapur J Microbiol. 2009;2(2):65-70.

16. Lawshe $\mathrm{CH}$. A quantitative approach to content validity. Person Psychol. 1975;28(4):563-75.

17. Taherdoost $\mathrm{H}$. Validity and reliability of the research instrument; how to test the validation of a questionnaire/survey in a research. How to test the validation of a questionnaire/survey in a research. Int J Acad Res Manage. 2016;5(3):28-36

18. Cronbach $\amalg$. Coefficient alpha and the internal structure of tests. Psychometrika. 1951;16(3):297-334.

19. Bartko JJ. The intraclass correlation coefficient as a measure of reliability. Psychol Rep. 1966;19(1):3-11

20. Gouya MM. Educational guideline and national instructions for Pediculosis and Scabies. Infectious Disease Management Center Iranian Ministry of Health and Medical Education, Tehran. 2016; 36-48. (in Persian). Available at: https://borkhar.mui.ac.ir/sites/borkhar.mui.ac. ir/files/9383.pdf
21. Nazari M, Azizi A. Epidemiological pattern of scabies and its social determinant factors in west of Iran. Health. 2014:6,1972-77.

22. Sharif $M$, Hezar Jaribi $H$, Haghi F. Prevalence of mange among primary school students in Sari during 1999-2000. J Mazandaran Univ Med Sci. 2003;13(38):49-53 (In Persian with English abstract).

23. Daliri S, Shafiei A. Scabies and impetigo in primary school students in Anzali port. World Health J. 1994;2(9):57-9 (In Persian with English abstract).

24. Ogunbiyi AO, Owoaje E, Ndahi A. Prevalence of skin disorders in school children in Ibadan, Nigeria. Pediatr Dermatol. 2005;22(1):6-10.

25. Nanda A, Al-Hasawi F, Alsaleh QA. A prospective survey of pediatric dermatology clinic patients in Kuwait: an analysis of 10,000 cases. Pediatr Dermatol. 1999;16(1):6-11.

26. Hegab DS, Kato AM, Kabbash IA, Dabish GM. Scabies among primary schoolchildren in Egypt: sociomedical environmental study in Kafr El-Sheikh administrative area. Clin Cosmet Investig Dermatol. 2015;8:105-11.

27. Inanir I, Şahin MT, Gündüz K, Dinç G, Türel A, Öztürkcan S. Prevalence of skin conditions in primary school children in Turkey: differences based on socioeconomic factors. Pediatr Dermatol. 2002;19(4):307-11.

28. Sarkar M. Personal hygiene among primary school children living in a slum of Kolkata, India. J Prev Med Hyg. 2013;54(3):153.

29. Kouotou EA, Nansseu JR, Kouawa MK, Bissek AC. Prevalence and drivers of human scabies among children and adolescents living and studying in Cameroonian boarding schools. Parasit Vectors. 2016;9(1):400.

30. Azene AG, Aragaw AM, Wassie GT. Prevalence and associated factors of scabies in Ethiopia: systematic review and Meta-analysis. BMC Infect Dis. 2020; 20(1):380

31. van der Linden N, van Gool K, Gardner K, Dickinson H, Agostino J, Regan $D G$, et al. A systematic review of scabies transmission models and data to evaluate the cost-effectiveness of scabies interventions. PLoS Negl Trop Dis. 2019;13(3):e0007182.

32. Mellanby K. The development of symptoms, parasitic infection and immunity in human scabies. Parasitology. 1944;35(4):197-206.

33. Arlian LG, Morgan MS. A review of Sarcoptes scabiei: past, present and future. Parasit Vectors. 2017:10(1):297.

34. Ugbomoiko US, Oyedeji SA, Babamale OA, Heukelbach J. Scabies in resource-poor communities in Nasarawa state, Nigeria: epidemiology, clinical features and factors associated with infestation. Trop Med Infect Dis. 2018;3(2):59.

35. Chaudhry FR, Hameed K, Naz S, Min DA, Paolotizzani RA. Scabies prevalence and risk factors in Pakistan: A hospital based survey. Biomed J Sci Tech Res. 2018;2(2): 2498-2502.

36. Gunathilaka N, Chandrasena N, Udayanga L. Prevalence of Ectoparasitic Infections and Other Dermatological Infections and Their Associated Factors among School Children in Gampaha District, Sri Lanka. Can J Infect Dis Med Microbiol. 2019:2019:5827124.

37. Yaseen $U$, Hassan I. Prevalence of various skin disorders in school going children of Kashmir valley of North India: a cross-sectional study. Indian J Paediatr Dermatol. 2013;14(3):67.

38. Amin T, Ali A, Kaliyadan F. Skin disorders among male primary school children in Al Hassa, Saudi Arabia: prevalence and socio-demographic correlates-a comparison of urban and rural populations. Rural Remote Health. 2011;11(1):1517.

39. Feldmeier $\mathrm{H}$, Jackson A, Ariza L, Calheiros CML, de Lima Soares V, Oliveira FA, et al. The epidemiology of scabies in an impoverished community in rural Brazil: presence and severity of disease are associated with poor living conditions and illiteracy. J Am Acad Dermatol. 2009;60(3):436-43.

40. Karim S, Anwar K, Khan M, Mollah M, Nahar N, Rahman H, et al. Sociodemographic characteristics of children infested with scabies in densely populated communities of residential madrashas (Islamic education institutes) in Dhaka, Bangladesh. Public Health. 2007; 121(12):923-34.

41. Sanei-Dehkordi A, Soleimani-Ahmadi M, Zare M, Madani A, Jamshidzadeh A. Head Lice Infestation (Pediculosis) and Its Associated Factors among Primary School Girls in Sirik County, Southern Iran. Int J Pediatr 2017:5(12): 6301-6309.

42. Soleimani-Ahmadi M, Jaberhashemi SA, Zare M, Sanei-Dehkordi A. Prevalence of head lice infestation and pediculicidal effect of permethrine shampoo in primary school girls in a low-income area in southeast of Iran. BMC Dermatol. 2017;17(1):10.

43. Tefera S, Teferi M, Ayalew A, Belete T, Hadush H. Prevalence of Scabies and Associated Factors among Primary School Children in Raya Alamata District, Tigray, Ethiopia, 2017/2018. J Infect Dis Epidemiol. 2020;6:154. 
44. Romani L, Whitfeld MJ, Koroivueta J, Kama M, Wand H, Tikoduadua L, et al. The epidemiology of scabies and impetigo in relation to demographic and residential characteristics: baseline findings from the skin health intervention Fiji trial. Am J Trop Med Hyg. 2017; 97(3):845-850.

45. Landwehr D, Keita SM, Pönnighaus JM, Tounkara C. Epidemiologic aspects of scabies in Mali, Malawi, and Cambodia. Int J Dermatol. 1998;37(8):588-90.

46. Wochebo W, Haji Y, Asnake S. Scabies outbreak investigation and risk factors in Kechabira district, Southern Ethiopia: unmatched case control study. BMC Res Notes. 2019;12(1):305.

47. Chouela E, Abeldaño A, Pellerano G, Hernández MI. Diagnosis and treatment of scabies. Am J Clin Dermatol. 2002;3(1):9-18.

48. Wang CH, Lee SC, Huang SS, Kao YC, See LC, Yang SH. Risk factors for scabies in Taiwan J Microbiol Immunol Infect. 2012;45(4):276-80.

49. Ahmed AE, Jradi H, AlBuraikan DA, ALMuqbil BI, Albaijan MA, Al-Shehri AM, et al. Rate and factors for scabies recurrence in children in Saudi Arabia: a retrospective study. BMC Pediatr. 2019;19(1):187.

\section{Publisher's Note}

Springer Nature remains neutral with regard to jurisdictional claims in published maps and institutional affiliations.

Ready to submit your research? Choose BMC and benefit from:

- fast, convenient online submission

- thorough peer review by experienced researchers in your field

- rapid publication on acceptance

- support for research data, including large and complex data types

- gold Open Access which fosters wider collaboration and increased citations

- maximum visibility for your research: over $100 \mathrm{M}$ website views per year

At $\mathrm{BMC}$, research is always in progress.

Learn more biomedcentral.com/submissions 